\title{
Correspondence
}

\section{Assessment and management of sexually abused children}

\section{DeAR SIRS}

Sometimes guidelines for a group of specialists are not only of great use to those specialists but of considerable value also to their colleagues in other specialties. I found that to be true of the report on 'Child Psychiatric Perspectives on the Assessment and Management of Sexually Mistreated Children' (Psychiatric Bulletin, December 1988, 12, 534-540).

As a paediatrician, I know that some child psychiatrists are heavily involved with child abuse and others barely at all, and I have wondered how the latter group manage to get away with it. Perhaps it is because of the statement on page 535 (ref 2, p. 22) that "child psychiatric intervention is only justified in cases of child sexual abuse where the child and/or the family displays psychiatrist disorder". Do the members of the working party who devised this report only wish child psychiatrists to be involved where there is gross overt disorder? Does it not think that there is perhaps some disorder in any family where child sexual abuse occurs?

I would be sad if child psychiatrists only became involved with child abuse when there was gross psychiatric disorder. Child abuse, and particularly sexual abuse, is difficult to deal with and child psychiatrists are in a strong position to deal with it better than most. In the first instance they ought to be better at talking with children and at discerning the truest version of events and helping with the initial disclosure: surely they are better at that than most social workers, police surgeons and paediatricians. Moreover with their understanding of families they must be in a better position to deal effectively with the turmoil that allegations of abuse produce for that family, and they ought to be effective in helping with the conflicting emotions and problems of social workers, nurses and doctors who are struggling to deal with child abuse.

The new committees replacing the former Area Review Committees are not mentioned in the report. I fear that sometimes these committees have not valued the potential contribution of child psychiatrists sufficiently.

In some districts there are three or four paediatricians on the committee but no child psychiatrist. Yet the duties of the committee include reviewing the arrangements for identifying and monitoring suitable training for professionals working with child abuse, and play an important role in bringing together some of the key people from different agencies concerned with child abuse. Child psychiatrists should stake their claim for a least one place on those committees.

Many of us may sigh when we encounter another abused child, and I am sure child psychiatrists must sigh as long and hard as anyone, because the ensuing work and worry will be immense. However, there are many people who recognise the volume of that work load and who wish that child psychiatrists would state more clearly that the only way that they can deal effectively with that work is by having more training posts and more consultant staff. If child psychiatrists do that they will be supported strongly by several allied specialties.

\section{Department of Paediatrics and Child Health} St James's University Hospital, Leeds

\section{DeAR SirS}

I read with interest the article on child abuse prepared by the Working Group of Child and Adolescent Specialist Section in the Psychiatric Bulletin (December 1988). I found it very readable, informative and of practical help, especially on difficult aspects such as confidentiality and interviewing abused children. Looking at the recent problems experienced by professionals working in the difficult area of child abuse, especially child sexual abuse, the great necessity is seen for a multidisciplinary approach and use of case conferences to facilitate communication between us (Butler-Sloss, 1987). The problem I have experienced is finding the time to attend these conferences as they are usually announced only at short notice and have to be accommodated into an already busy working week. Apparently, we may be able to claim for attending such case conferences unless it is written in our contracts that this service should be provided (Simmons, 1988).

I also found the section on "court work" interesting (Working Group of the Child and Adolescent Specialist Section, 1988). It does seem that child psychiatrists will be increasingly involved in court related work but they have little training in court work unless they have had, like me, the opportunity of accompanying one's consultant to court. The training we do have tends to be acquired when we are actually performing in court. Finally, courts can be very demanding of our time and although the courts state that they do give priority to "invalids and doctors", this does not always happen and we can find ourselves waiting outside court for what seems, 